\title{
Caracterização de Isolados de Ralstonia solanacearum Obtidos de Tomateiros em Várzea e em Terra Firme, no Estado do Amazonas
}

\author{
Rosalee A. Coelho Netto ${ }^{1}$, Bianca G. Pereira ${ }^{1}$, Hiroshi Noda ${ }^{1}$ \& Bernard Boher $^{2}$ \\ 'Instituto Nacional de Pesquisa da Amazônia, Coordenação de Pesquisa em Ciências Agronômicas, Cx. Postal 478, \\ CEP 69011-670, Manaus, AM, e-mail: rcoelho@ inpa.gov.br; ${ }^{2}$ UR 075, Résistance des Plantes, Centre IRD, B.P. 5045, \\ 34032 Montpellier, France
}

(Aceito para publicação em 10/06/20 03)

Autor para correspondência: Rosalee A. Coelho Netto

COELHO NETTO, R.A., PEREIRA, B.G., NODA, H. \& BOHER, B. Caracterização de isolados de Ralstonia solanacearum obtidos de tomateiros em várzea e em terra firme, no Estado do Amazonas. Fitopatologia Brasileira 28:362-366. 2003.

\section{RESUMO}

A variabilidade de isolados de Ralstonia solanacearum, provenientes de tomateiros (Lycopersicon esculentum) do Estado do Amazonas, foi estudada com relação à agressividade, à sensibilidade a bacteriocinas e às características bioquímicas. Três experimentos foram estabelecidos em áreas naturalmente infestadas com $R$. solanacearum sendo um em terra firme, em 1998, e dois em uma mesma área de várzea, em 1998 e em 2000. Em cada experimento, 200 mudas de tomateiros da cv Yoshimatsu (resistente) e 200 da cv. Santa Cruz Kada (suscetível) foram plantadas alternadas em um espaçamento de $1 \mathrm{~m}$ entre fileiras e $0,5 \mathrm{~m}$ entre plantas. Semanalmente, isolou-se a bactéria, a partir de plantas apresentando sintomas de murcha. Obtiveram-se, nos três experimentos, 267 isolados pertencentes aos biovares $1(67,8 \%)$ e $3(32,2 \%)$. Em terra firme, $80,4 \%$ dos isolados obtidos eram do biovar 1 enquanto que em várzea, os isolados do biovar 1 foram 37,4 e 87,8\%, nos ensaios de 1998 e de 2000, respectivamente. Com base na sensibilidade a bacteriocinas os isolados foram divididos em sete grupos, sendo que dois deles englobaram $80,5 \%$ do total dos isolados. Através da reação apresentada por 15 plantas de tomate, de berinjela (Solanum melongena) e de pimentão (Capsicum annuum), inoculadas um mês após a semeadura, a agressividade de isolados selecionados foi avaliada. Os isolados do biovar 1 foram mais agressivos sobre tomateiros que os do biovar 3 . Estes últimos, no entanto, foram mais agressivos sobre pimentão e berinjela. Em várzea, as plantas da cv. Yoshimatsu tiveram 50,5\% de mortalidade contra $22,5 \%$, em terra firme, comprovando a importância do fator ambiente na ocorrência da doença.

Palavras-chave adicionais: murcha bacteriana, Lycopersicon esculentum, bacteriocinas.

\section{ABSTRACT}

Characterization of Ralstonia solanacearum isolates obtained from tomatoes in the field subject to periodic flooding and nonflooded fields in the Amazonas State

The variability of Ralstonia solanacearum isolates obtained from tomato (Lycopersicon esculentum) plants in the Amazonas State was studied for pathogen aggressiveness, bacteriocin sensitivity and for biochemical characteristics. Three experiments were established in areas naturally infested with $R$. solanacearum. These were: (i) in a non-flooded area of a field in 1998, (ii) in an periodically-flooded area, in 1998, and (iii) in the same periodically-flooded area in 2000. In each experiment there were 200 resistant tomato plants (cv. Yoshimatsu) and 200 susceptible (cv. Santa Cruz Kada) planted by alternating resistant and susceptible cultivars. From the 267 isolates obtained from plants exhibiting wilt symptoms, $67.8 \%$ belonged to biovar 1 and $32.2 \%$ to biovar 3. In the non-flooded soil, $80.4 \%$ of he isolates collected were found to be biovar 1 , whereas in fields periodically-flooded, the percentage of biovar 1 isolates was 37.4 and $87.8 \%$ for the 1998 and 2000 experiments, respectively. Based on bacteriocin sensitivity classification, isolates were divided into seven groups and two of these groups accounted for $80.5 \%$ of the isolates. The aggressiveness of selected isolates was evaluated in tomato, eggplant (Solanum melongena) and sweet pepper (Capsicum annuum) plants. Biovar 1 isolates were more aggressive on tomato than biovar 3 isolates. Biovar 3, however, was more aggressive on sweet pepper and eggplant than biovar 1. In fields subject to periodic flooding, cv. Yoshimatsu had $50.5 \%$ mortality versus $22.5 \%$ mortality in the nonflooded field. This indicates the importance of this environmental factor on disease occurrence.

\section{INTRODUÇÃO}

Ralstonia solanacearum (Smith) Yabuuchi et al., agente causador da murcha-bacteriana em numerosos hospedeiros, apresenta elevada variabilidade fenotípica. Tradicionalmente, a espécie tem sido dividida em cinco raças e em cinco biovares, com base na reação sobre uma gama de hospedeiros e em propriedades bioquímicas, respectivamente (Hayward, 1994). Não há, entretanto, uma relação perfeita entre a diferenciação de raças e a classificação em biovares (Buddenhagen \& Kelman, 1964). Numa mesma raça têm sido agrupados isolados de diferentes fenótipos, de distintos genótipos e filogenia (Hayward, 1994).

A murcha-bacteriana do tomateiro (Lycopersicon esculentum Mill.), causada pela raça 1 de $R$. solanacearum, é uma doença limitante para essa cultura, na Região Amazônica. Cultivando tomateiros suscetíveis, o agricultor dessa região expõe-se a prejuízos que podem ser totais (Noda et al., 1986). 
Em condições de alta infestação do solo, o controle da doença envolve, necessariamente, o uso de cultivares resistentes. A expressão da resistência, no entanto, está fortemente correlacionada com condições ambientais como temperaturas elevadas e altos níveis de umidade do solo (Mew \& Ho, 1977). Infestação por nematóides (Napiere, 1980, Cadet et al., 1989) e a variabilidade da agressividade de isolados locais de $R$. solanacearum são também fatores relacionados com o aumento da severidade da doença ou com a quebra da resistência (Prior \& Steva, 1990; Darasse et al., 1998).

Na Amazônia encontram-se dois ecossistemas bem definidos, o de várzea, com solos de boa fertilidade e temporariamente inundáveis, e o de terra firme, com solos mais pobres e sempre livres das enchentes. Visando analisar a variabilidade de isolados de $R$. solanacearum, nesses dois ecossistemas, com relação a agressividade, sensibilidade a bacteriocinas e a características bioquímicas, foi realizado o presente trabalho.

\section{MATERIALEMÉTODOS}

Dois ensaios idênticos foram instalados no período das chuvas (março/maio), em 1998, em áreas naturalmente infestadas $\operatorname{com} R$. solanacearum. Um dos ensaios foi instalado, em área de várzea, na Estação Experimental do Ariaú, do INPA, no município de Iranduba, e o outro, em área de terra firme, na Estação Experimental de Hortaliças “Alejo von der Pahlen”, localizada no $\mathrm{km} 14$ da rodovia AM 10, município de Manaus. Nessas áreas foram estabelecidas 200 mudas de tomateiros da cultivar suscetível Santa Cruz Kada e 200, da cultivar resistente Yoshimatsu, em posições alternadas, com espaçamento de 1,0 m entre fileiras e 0,5 m entre plantas. Em 2000, no período de janeiro a abril, o ensaio foi repetido, na Estação Experimental do Ariaú, na mesma localização do ensaio anterior. Em avaliações semanais foram anotadas as plantas apresentando sintoma de murcha, com escurecimento dos vasos e exsudação bacteriana e as plantas mortas. Para cada planta com sintoma foi feito isolamento do patógeno, a partir dos tecidos escurecidos do xilema do caule, em zonas de progressão da doença. Os isolados foram caracterizados bioquimicamente através dos seguintes testes: solubilidade em hidróxido de potássio, oxidase, hidrólise do amido, atividade de esterase (hidrólise do Tween), redução do nitrato, crescimento em meio contendo $2 \%$ de cloreto de sódio e hipersensibilidade em folha de fumo (Nicotiana tabacum L.) (Fahy \& Persley, 1983). O teste para determinação do biovar foi realizado em tubos de micro-centrífuga Eppendorf ${ }^{\circledR}$, com capacidade de 1,5 ml e contendo $1,0 \mathrm{ml}$ de meio básico com as fontes de carbono $\left(\right.$ Sigma $\left.^{\circledR}\right)$ lactose, maltose, celobiose, manitol, dulcitol e sorbitol (Hayward, 1976).

A produção e a avaliação da sensibilidade a bacteriocinas seguiu a metodologia descrita por Cuppels et al. (1978). Quatro isolados de $R$. solanacearum, três do biovar 1 e um do biovar 3, obtidos nos ensaios de campo, foram selecionados como produtores de bacteriocinas e 267 isolados, também obtidos nos ensaios de campo, foram avaliados quanto a sensibilidade às bacteriocinas produzidas pelos primeiros. Para a produção de bacteriocinas, os quatro isolados foram cultivados em meio CPG líquido, sob agitação, a $26^{\circ} \mathrm{C}$, durante três dias. As bactérias foram separadas por centrifugação (4500 rpm por $20 \mathrm{~min}$ ) e o sobrenadante esterilizado por ultrafiltração (Millipore ${ }^{\circledR} 0,45 \mu \mathrm{m}$ ). Dez microlitros dos quatro filtrados foram depositados na superfície de uma camada constituída de uma mistura de $50 \mu 1$ da suspensão de bactérias de cada um dos 267 isolados, separadamente, contendo $10^{5} \mathrm{ufc} / \mathrm{ml}$, com $4 \mathrm{ml}$ de meio CPG, com 0,8\% de ágar, fundente, distribuída em placa de Petri, contendo uma camada de ágar-água. Após 24 h de incubação a $29{ }^{\circ} \mathrm{C}$, zonas translúcidas, sem crescimento bacteriano, indicavam uma sensibilidade do isolado presente na camada de meio de cultura.

A agressividade de 37 isolados selecionados, sendo 23 do biovar 1 e 14 do biovar 3 foi avaliada sobre tomateiros, cv. Yoshimatsu. Desses isolados, 32 foram inoculados em mudas de pimentão (Capsicum annuum L.) cv. Yolo Wonder e 27 em mudas de berinjela (Solanum melongena L.) cv. Embu, cultivadas em casa de vegetação $\left(25^{\circ} \mathrm{C}-38^{\circ} \mathrm{C}\right)$. Quinze plantas, divididas em cinco vasos contendo $500 \mathrm{ml}$ de terra misturada com composto vegetal, na proporção de $3: 1$ (v:v) e esterilizada em autoclave, foram inoculadas 30 dias após a semeadura, para cada isolado em teste. Para a inoculação, feriram-se as raízes da plantas, introduzindo-se um esclapelo no solo, em torno da base das mesmas e, imediatamente, verteram-se no solo, sobre as raízes feridas, 5,5 $\mathrm{ml}$ de suspensão de bactérias $\left(10^{8} \mathrm{ufc} / \mathrm{ml}\right)$ por planta. Os sintomas foram avaliados, no período da manhã, aos quatro, seis, oito, dez, 12 e 14 dias após inoculação, através da quantificação do percentual de folhas murchas. Com esses valores, foi calculada a área abaixo da curva de progresso da doença (AACPD) para cada par isolado/ hospedeiro (Campbell \& Madden, 1990).

\section{RESULTADOS}

Nos ensaios de 1998, ficou evidente a maior suscetibilidade da cv. Santa Cruz Kada que apresentou 78,5\% e 98,5\% de plantas mortas, no final do cultivo, nas áreas de terra firme e de várzea, respectivamente. Para a cv. Yoshimatsu, os níveis de infecção foram de 22,5\% e 50,5\%, nas mesmas áreas (Figura 1). $\mathrm{Na}$ várzea, ficou evidenciado um menor período de incubação da doença, em comparação com a área de terra firme.

A partir das plantas com sintomas de murcha, nos dois ensaios de 1998 e no ensaio de 2000, foram obtidos e caracterizados 267 isolados de $R$. solanacearum sendo 91, no ensaio em área de várzea, 102 no ensaio em área de terra firme, em 1998 e 74 em área de várzea, no ano 2000. Os biovares 1 e 3 foram encontrados nos três ensaios (Tabela 1). Em várzea, o biovar 3 predominou em 1998, tendo sido o biovar 1 identificado com maior freqüência em área de terra firme, no mesmo ano, e em área de várzea, no ano 2000. Não foi constatada nenhuma relação entre o biovar isolado e as características de resistência da planta de origem (Tabela 2).

O resultado das confrontações entre os 267 isolados e as quatro soluções de bacteriocinas, revelou a presença de sete diferentes grupos de sensibilidade. Dentro desses, os 
R.A. Coelho Netto et al.
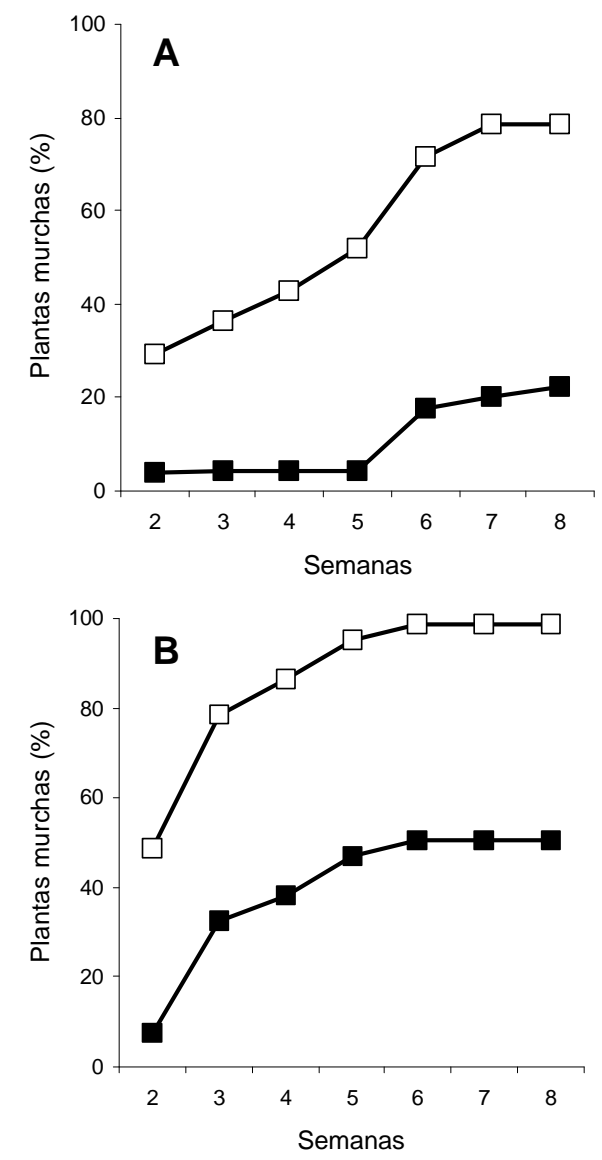

FIG. 1 - Percentual semanal de morte, devido à murcha-bacteriana, em tomateiros (Lycopersicom esculentum) das cultivares Yoshimatsu, (ロ) e Santa Cruz Kada, ( $\square$ ), em terra firme (A) e em várzea (B), no estado do Amazonas, em 1998.

grupos 1 e 2 apresentaram uma freqüência elevada, atingindo $45,6 \%$ e $33,7 \%$ da população analisada, respectivamente, nos ensaios de 1998 (Tabela 3). No ensaio de várzea, em 2000, a proporção de isolados pertencentes ao grupo 2 foi de $75,7 \%$ do total enquanto que os do grupo 1, representaram apenas $8,1 \%$ do total, naquele ano. No grupo 1 , encontraram-se apenas isolados do biovar 3, nos ensaios de várzea de 1998 e 2000, e isolados dos biovares 1 e 3, no ensaio de terra firme, em 1998.

TABELA 1 - Freqüência de isolados de Ralstonia solanacearum pertencentes aos biovares 1 e 3 provenientes de tomateiros (Lycopersicon esculentum) de áreas de várzea e de terra firme, obtidos de cultivares suscetível, Santa Cruz Kada, ou resistente ,Yoshimatsu, no estado do Amazonas em 1998 e 2000

\begin{tabular}{lrrrrr}
\hline \hline \multirow{2}{*}{ Isolado } & \multicolumn{3}{c}{ Freqüência } & & \multirow{2}{*}{ Total } \\
\cline { 2 - 3 } & \multicolumn{2}{c}{1998} & & $\mathbf{2 0 0 0}$ & \\
\cline { 2 - 3 } & Várzea & Terra Firme & Várzea & \\
\hline Bv 1 & $34(37,4 \%)$ & $82(80,4 \%)$ & & $65(87,8 \%)$ & $181(67,8 \%)$ \\
Bv 3 & $57(62,6 \%)$ & $20(19,6 \%)$ & & $9(12,2 \%)$ & $86(32,2 \%)$ \\
\hline Total & $91(100 \%)$ & $102(100 \%)$ & $74(100 \%)$ & $267(100 \%)$ \\
\hline
\end{tabular}

TABELA 2 - Percentagem de isolados dos biovares 1 e 3 de Ralstonia solanacearum provenientes de tomateiros (Lycopersicon esculentum) suscetível (Santa Cruz Kada) e resistente (Yoshimatsu), em várzea e em terra firme no estado do Amazonas, em 1998

\begin{tabular}{lccccc}
\hline \hline \multirow{2}{*}{ Biovar } & \multicolumn{2}{c}{ Várzea } & & \multicolumn{2}{c}{ Terra Firme } \\
\cline { 2 - 3 } \cline { 5 - 6 } & Suscetível & Resistente & & Suscetível & Resistente \\
\hline 1 & 33,3 & 37,8 & & 71,0 & 83,3 \\
3 & 66,7 & 62,2 & & 24,0 & 16,7 \\
\hline
\end{tabular}

O grupo 2 foi formado apenas com isolados do biovar 1, nos três ensaios, assim como os grupos 3, 4 e 5. Isolados dos dois biovares formaram os grupos 6 e 7 .

Uma grande variabilidade na agressividade foi observada através dos valores da AACPD (Tabela 4). Os isolados, de maneira geral, foram mais agressivos para tomateiros e menos agressivos para plantas de pimentão e de berinjela. Alguns isolados como K13 e A83 foram altamente agressivos sobre os três hospedeiros enquanto que outros como A19, A38 e A2 apresentaram agressividade média ou baixa, sobre os mesmos hospedeiros. Observou-se também especificidade entre isolados como A66 e K50 que foram altamente agressivos para tomateiros e pouco agressivos para plantas de pimentão e de berinjela, respectivamente e isolados como A1 e A26 que foram medianamente agressivos para tomateiros e altamente agressivos para plantas de pimentão e de berinjela. A variabilidade na agressividade foi encontrada tanto no biovar 1 quanto no 3 .

\section{DISCUSSÃO}

O percentual de mortalidade elevado, observado nos tomateiros suscetíveis (Figura 1), confirmam a importância da murcha-bacteriana como fator limitante do cultivo de tomateiros no Estado do Amazonas. A resistência da cv. Yoshimatsu foi maior em terra firme do que na várzea. Em terra firme, essa cultivar apresentou mortalidade de $28,6 \%$ da observada na cv. Santa Cruz Kada e, em terra firme, 50,5\% menor, confirmando a importância do ambiente na ocorrência da doença.

A temperatura elevada, um dos fatores mais citados como causa da diminuição da resistência do tomateiro (Prior $e t$ al., 1994), não pode ser considerada nesse caso, pois foi a mesma nas duas localidades. A ocorrência de períodos de encharcamento, observados no solo argiloso da várzea, e que não ocorreram no solo arenoso, da terra firme, é a causa mais provável para explicar a maior infecção nas plantas da várzea. $\mathrm{Na}$ época da cheia, o encharcamento do solo pode causar morte de parte dos tecidos das raízes, por deficiência de oxigênio e, quando o solo seca, pode haver quebra de raízes. Ambos os fenômenos produzem aberturas para penetração da bactéria, favorecendo uma rápida colonização da planta. Os sintomas de infestação de nematóides, outra causa conhecida da quebra de resistência, não foram observados no ensaio de várzea e foram quase inexistentes, no ensaio de terra firme.

Dos três biovares encontrados infetando tomateiros 
Caracterização de isolados de Ralstonia solanacearum obtidos de tomateiros em...

TABELA 3 - Freqüência (\%) de isolados de Ralstonia solanacearum obtidos de tomateiros (Lycopersicon esculentum) e provenientes de várzea e de terra firme em 1998 e de várzea em 2000, classificadas em grupos de sensibilidade a bacteriocinas (GSB)

\begin{tabular}{|c|c|c|c|c|c|c|c|c|c|c|c|}
\hline \multirow{3}{*}{ GSB } & \multicolumn{7}{|c|}{1998} & \multirow{2}{*}{\multicolumn{3}{|c|}{$\begin{array}{c}2000 \\
\text { Várzea }\end{array}$}} & \multirow{3}{*}{$\begin{array}{c}\text { Total } \\
\% \\
\end{array}$} \\
\hline & \multicolumn{3}{|c|}{ Várzea } & \multicolumn{3}{|c|}{ Terra Firme } & \multirow{2}{*}{$\begin{array}{c}\text { Total } \\
\% \\
\end{array}$} & & & & \\
\hline & Bvl & Bv3 & $\%$ & Bv1 & Bv3 & $\%$ & & Bv1 & Bv3 & $\%$ & \\
\hline 1 & 0 & 43 & 47,3 & 28 & 17 & 44,1 & 45,6 & 0 & 6 & 8,1 & 35,2 \\
\hline 2 & 30 & 0 & 33 & 35 & 0 & 34,3 & 33,7 & 56 & 0 & 75,7 & 45,3 \\
\hline 3 & 3 & 0 & 3,3 & 6 & 0 & 5,9 & 4,7 & 1 & 0 & 1,4 & 3,7 \\
\hline 4 & 0 & 0 & 0 & 7 & 0 & 6,9 & 6,6 & 3 & 0 & 4,1 & 3,7 \\
\hline 5 & 0 & 0 & 0 & 1 & 0 & 1,0 & 0,5 & 0 & 0 & 0 & 0,4 \\
\hline 6 & 0 & 11 & 12,1 & 3 & 3 & 5,9 & 8,8 & 5 & 3 & 10,8 & 9,4 \\
\hline 7 & 1 & 3 & 4,4 & 2 & 0 & 1,9 & 3,1 & 0 & 0 & 0 & 2,3 \\
\hline
\end{tabular}

no Estado do Amazonas, 1, N2 e 3 (Boher et al., 1999), apenas os biovares 1 e 3 foram encontrados nos três ensaios (Tabela 1). Os isolados do biovar 3, que eram maioria no ensaio de várzea em 1998, tornaram-se minoria, na mesma localização, em 2000. Um cultivo de pimentão antecedeu o estabelecimento do ensaio na área de várzea, em 1998, podendo ter sido responsável pelo aumento da população de isolados do biovar 3, no local. A forte agressividade dos isolados do biovar 3 para plantas de pimentão, e o fato do biovar 3 ser proporcionalmente mais freqüente nesse hospedeiro (Coelho Netto et al., 2003), contribuem a favor dessa hipótese.

A diferenciação dos isolados em grupos de sensibilidade a bacteriocinas mostrou-se ligada à classificação em biovares (Tabela 3). Este fato foi também observado por Frey et al. (1996) analisando isolados provenientes de tomateiros de Guadalupe. Os mesmos autores constataram uma forte correlação entre os grupos definidos, através da sensibilidade a bacteriocinas, e aqueles definidos por caracterização molecular (rep-PCR, RC-PFGE). A diferenciação dos isolados em grupos de sensibilidade a bacteriocinas evidenciou que mudanças rápidas podem acontecer dentro das populações clonais, em uma área de cultivo. A utilidade desse método na caracterização das populações de bactérias, no entanto, tem limites. Um deles, reside nas mutações freqüentes, que foram observadas alterando a sensibilidade a bacteriocinas, de várias espécies de bactérias (Dykes, 1995). A ocorrência de mutação poderia ser usada para explicar a presença de isolados do biovar 1, no ensaio de terra firme, no grupo 1 de sensibilidade a bacteriocinas, que foi constituído apenas por isolados do biovar 3, nos ensaios de várzea em 1998 e em 2000 (Tabela 3).

A variabilidade na agressividade de isolados dos biovares 1 e 3, ao tomateiro, foi constatada por Martins et al. (1988) e por Lopes et al. (1994). Silveira et al. (1998), entretanto, conduzindo estudo semelhante, não constataram diferença na agressividade dos isolados avaliados. Lopes et al. (1994) observaram maior agressividade, sobre tomateiros, dos isolados pertencentes ao biovar 1 . O cálculo da AACPD, em plantas de
TABELA 4 - Agressividade de isolados de Ralstonia solanacearum provenientes de tomateiros (Lycopersicon esculentum) de várzea (isolados A) e de terra firme (isolados K) do estado do Amazonas, avaliada pela AACPD da murcha-bacteriana em plantas de tomate, berinjela (Solanum melongena) e pimentão (Capsicum annuиm)

\begin{tabular}{|c|c|c|c|c|c|}
\hline \multirow{2}{*}{ Isolado } & \multirow{2}{*}{ Biovar } & \multirow{2}{*}{ GSB $^{1}$} & \multicolumn{3}{|c|}{ AACPD } \\
\hline & & & Tomate & Berinjela & Pimentão \\
\hline A5 & 1 & 7 & $900,87 \mathrm{a}^{2}$ & $536,93 \mathrm{~b}$ & $359,33 \mathrm{~b}$ \\
\hline A66 & 1 & 2 & $855,20 \mathrm{a}$ & $457,60 \mathrm{c}$ & $133,87 \mathrm{~d}$ \\
\hline K105 & 1 & 2 & $853,40 \mathrm{a}$ & $468,80 \mathrm{c}$ & $390,00 \mathrm{~b}$ \\
\hline $\mathrm{K} 2$ & 1 & 2 & $817,60 \mathrm{a}$ & $477,71 \mathrm{c}$ & -3 \\
\hline K8 & 1 & 4 & $815,73 \mathrm{a}$ & $488,43 \mathrm{c}$ & $207,67 \mathrm{c}$ \\
\hline A36 & 1 & 2 & $790,33 \mathrm{a}$ & $406,20 \mathrm{c}$ & $295,00 \mathrm{c}$ \\
\hline A83 & 3 & 6 & $767,67 \mathrm{a}$ & $705,60 \mathrm{a}$ & $566,13 \mathrm{a}$ \\
\hline A12 & 1 & 2 & 756,13 a & $633,80 \mathrm{~b}$ & $377,20 \mathrm{~b}$ \\
\hline K70 & 1 & 3 & $754,40 \mathrm{a}$ & $292,21 \mathrm{~d}$ & - \\
\hline A99 & 1 & 2 & $733,29 a$ & $330,53 \mathrm{~d}$ & $69,33 \mathrm{~d}$ \\
\hline A27 & 1 & 2 & $719,87 \mathrm{a}$ & - & - \\
\hline K50 & 1 & 3 & $719,13 \mathrm{a}$ & $95,58 \mathrm{e}$ & - \\
\hline $\mathrm{K} 7$ & 1 & 1 & $718,00 \mathrm{a}$ & $625,03 \mathrm{~b}$ & $338,49 \mathrm{~b}$ \\
\hline A84 & 1 & 3 & $715,60 \mathrm{a}$ & $372,67 \mathrm{c}$ & $141,47 \mathrm{~d}$ \\
\hline K13 & 1 & 1 & $714,47 \mathrm{a}$ & $783,20 \mathrm{a}$ & $634,53 \mathrm{a}$ \\
\hline A45 & 1 & 2 & $703,20 \mathrm{a}$ & $507,73 \mathrm{c}$ & $86,47 \mathrm{~d}$ \\
\hline K45 & 3 & 1 & $693,13 \mathrm{~b}$ & $425,47 \mathrm{c}$ & - \\
\hline A58 & 1 & 2 & $687,04 \mathrm{~b}$ & $428,87 \mathrm{c}$ & $197,80 \mathrm{c}$ \\
\hline A41 & 3 & 6 & $670,60 \mathrm{~b}$ & $402,20 \mathrm{c}$ & $427,60 \mathrm{~b}$ \\
\hline A90 & 3 & 1 & $669,65 \mathrm{~b}$ & - & - \\
\hline A 33 & 3 & 6 & $664,73 \mathrm{~b}$ & $810,80 \mathrm{a}$ & $707,73 \mathrm{a}$ \\
\hline K39 & 1 & 4 & $664,07 \mathrm{~b}$ & $336,45 \mathrm{~d}$ & $286,64 \mathrm{c}$ \\
\hline $\mathrm{K} 27$ & 1 & 1 & $636,73 \mathrm{~b}$ & - & - \\
\hline $\mathrm{A} 13$ & 1 & 2 & $597,40 \mathrm{~b}$ & $418,07 \mathrm{c}$ & $147,87 \mathrm{c}$ \\
\hline A 15 & 3 & 1 & $595,20 \mathrm{~b}$ & $204,40 \mathrm{e}$ & $153,20 \mathrm{~d}$ \\
\hline A49 & 3 & 1 & $573,47 \mathrm{~b}$ & $561,53 \mathrm{~b}$ & $350,40 \mathrm{~b}$ \\
\hline K64 & 3 & 6 & $572,87 \mathrm{~b}$ & $715,43 \mathrm{a}$ & 585,47 a \\
\hline K34 & 1 & 1 & $550,20 \mathrm{~b}$ & $402,12 \mathrm{c}$ & $176,66 \mathrm{c}$ \\
\hline A22 & 3 & 1 & $539,13 \mathrm{~b}$ & $512,40 \mathrm{c}$ & $642,80 \mathrm{a}$ \\
\hline A26 & 3 & 6 & $503,53 \mathrm{c}$ & $735,60 \mathrm{a}$ & $644,47 \mathrm{a}$ \\
\hline $\mathrm{A} 2$ & 3 & 7 & $496,20 \mathrm{c}$ & $320,20 \mathrm{~d}$ & $27,67 \mathrm{~d}$ \\
\hline A38 & 3 & 1 & $430,09 \mathrm{c}$ & $153,40 \mathrm{e}$ & $132,40 \mathrm{~d}$ \\
\hline A102 & 1 & 3 & $414,67 \mathrm{c}$ & - & - \\
\hline A1 & 3 & 7 & $385,27 \mathrm{c}$ & $654,93 \mathrm{~b}$ & $447,73 \mathrm{~b}$ \\
\hline A19 & 1 & 3 & $295,60 \mathrm{~d}$ & $295,60 \mathrm{~d}$ & $20,13 \mathrm{~d}$ \\
\hline $\mathrm{K} 3$ & 3 & 1 & $163,67 \mathrm{~d}$ & $629,90 \mathrm{~b}$ & - \\
\hline $\mathrm{A} 48$ & 1 & 3 & $133,33 \mathrm{~d}$ & - & - \\
\hline
\end{tabular}

${ }^{1}$ Grupo de sensibilidade a bacteriocinas;

${ }^{2}$ Os valores seguidos pela mesma letra, na coluna, não diferem significativamente pelo teste de agrupamento de Scott-Knott a 5\% de probabilidade;

3 - = não inoculados.

berinjela, pimentão e tomate, evidenciou uma grande variabilidade da agressividade, entre os isolados (Tabela 4). Isolados altamente agressivos, assim como os pouco agressivos, pertenceram tanto ao biovar 1, quanto ao biovar 3 . No entanto, como observado quando os isolados foram classificados segundo a agressividade, 93,75\% dos isolados mais agressivos ao tomateiro foram do biovar 1 , enquanto que $83,3 \%$ dos mais agressivos ao pimentão e $80 \%$ dos mais 


\section{R.A. Coelho Netto et al.}

agressivos à berinjela foram do biovar 3. Assim, a resistência da cv. Yoshimatsu foi mais eficaz contra os isolados do biovar 3 do que contra os do biovar 1. Em área de várzea, os tomateiros da cv. Yoshimatsu, foram quase sempre expostos a uma maior população de bactérias do biovar 3 (Tabela 1), consideradas menos agressivas a essa cultivar. A cv. Yoshimatsu, no entanto, mostrou-se menos resistente na área de várzea. Esse fato pode indicar uma predominância do fator ambiente, sobre o fator patógeno, na infecção do hospedeiro no ecossistema de várzea.

\section{REFERÊNCIAS BIBLIOGRÁFICAS}

BOHER, B., BELÉM COSTA, S., SILVA FILHO, D.F., MACHADO, M.F. \& NODA, H. Ocorrência de três biovares de Ralstonia solanacearum em vários hospedeiros no Estado do Amazonas. Fitopatologia Brasileira 24:246-247. 1999.

BUDDENHAGEN, I.W. \& KELMAN, A. Biological and physiological aspects of bacterial wilt caused by Pseudomonas solanacearum. Annual Review of Phytopathology 2:203-230. 1964.

CAMPBELL, C.L. \& MADDEN, L.V. Introduction to Plant Disease Epidemiology. New York. John Wiley \& Sons, 1990.

CADET, P., PRIOR, P. \& STEVA, H. Influence de Meloidogyne arenaria sur la sensibilité de deux cultivars de tomate à Pseudomonas solanacearum (E.F. Smith), dans les Antilles françaises. Agronomia Tropical 44:263-268. 1989.

COELHO NETTO, R.A., PEREIRA, B.G., NODA, H \& BOHER, B. Murcha bacteriana no estado do Amazonas, Brasil. Fitopatologia Brasileira. 2003 (no prelo).

CUPPELS, D.A., HANSON, R.S. \& KELMAN, A. Isolation and characterization of bacteriocin produced by Pseudomonas solanacearum. Journal of General Microbiology 109:295-303. 1978.

DYKES, G.A. Bacteriocins: ecological and evolutionary significance. TREE 10:186-189. 1995.

DARRASSE, A., TRIGALET, A. \& PRIOR, P. Correlation of aggressiveness with genomic variation in Ralstonia solanacearum Race 1. Prior, P., Allen, C. \& Elphinstone J. (Eds.). Bacterial Wilt Disease. Molecular and Epidemiological Aspects. Berlin. SpringerVerlag. 1998. pp. 89-98.

FAHY, P.C. \& PERSLEY, G.J. Plant bacterial diseases. A diagnostic guide. Sydney. Academic Press. 1983.

FREY, P., SMITH, J.J., ALBAR, L., PRIOR, P., SADDLER, GS.,
TRIGALET-DEMERY, D. \& TRIGALET, A. Bacteriocin typing of Burkholderia (Pseudomonas) solanacearum Race 1 of the French West Indies and correlation with genomic variation of the pathogen. Applied and Environmental Microbiology 62:473-479. 1996.

HAYWARD, A.C. Technique for the study of Pseudomonas solanacearum. In: Sequeira, L. \& Kelman A. (Eds.). Proceedings of the First International Planning Conference and Workshop on the Ecology and Control of Bacterial Wilt Caused by Pseudomonas solanacearum. Raleigh. North Carolina State University. 1976. pp.137-142.

HAYWARD, A.C. Systematics and phylogeny of Pseudomonas solanacearum and related bacteria. In: Hayward, A.C. \& Hartman, G.L. (Eds.). Bacterial wilt: The disease and its causative agent, Pseudomonas solanacearum. Wallingford. CAB. 1994. pp.123-135. LOPES, C.A., QUEZADO-SOARES, A.M. \& MELO, P.E. Differential resistance of tomato cultigens to biovares I e III of Pseudomonas solanacearum. Plant Disease 78:1091-1094. 1994.

MARTINS, O.M., TAKATSU, A. \& REIFSCHNEIDER, F.J.B. Virulência de biovares I e III de Pseudomonas solanacearum ao tomateiro. Fitopatologia Brasileira 13:249-252. 1988.

MEW, T.W. \& HO, W.C. Effect of soil temperature on resistance of tomato cultivars to bacterial wilt. Phytopathology 67:909-911. 1977.

NAPIERE, C.M. Varying inoculum levels of bacteria-nematodes and the severity of tomato bacterial wilt. Annals of Tropical Research 2:129-134. 1980.

NODA, H., PAHLEN, A.V. DER, SILVA FILHO, D.F. Avaliação da resistência de progênies de tomate à murcha bacteriana em solo naturalmente infestado por Pseudomonas solanacearum (Smith) Dows. Revista Brasileira de Genética 9:55-66. 1986.

PRIOR, P. \& STEVA, H. Characteristics of strains of Pseudomonas solanacearum from the French West Indies. Plant Disease 74:1317. 1990.

PRIOR, P., GRIMAULT, V. \& SCHMIT, J. Resistance to bacterial wilt (Pseudomonas solanacearum) in tomato: present status and prospects. In: Hayward, A.C. \& Hartman, G.L. (Eds.). Bacterial wilt: The disease and its causative agent, Pseudomonas solanacearum. Wallingford. CAB. 1994. pp.209-223.

SILVEIRA, E.B., GOMES, A.M.A., MICHEREFF, S.J. \& MARIANO, R.L. Variability of Ralstonia solanacearum populations causing wilt of tomato in Agreste of Pernambuco, Brazil. Bacterial Wilt Newsletter, 15:8-10. 1998. 